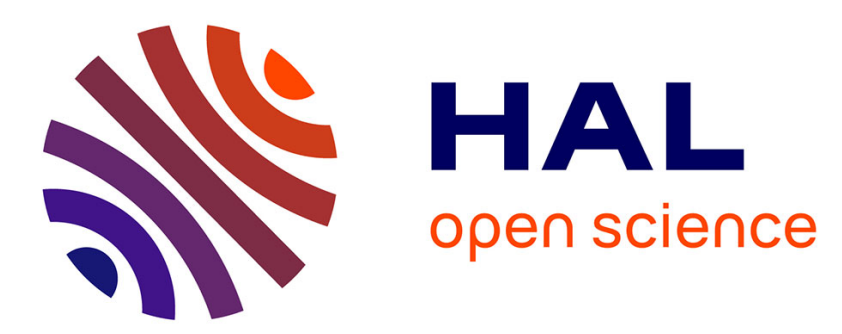

\title{
Bubble on Real Estate: The Role of Altruism and Fiscal Policy
}

Lise Clain-Chamosset-Yvrard, Thomas Seegmuller

\section{To cite this version:}

Lise Clain-Chamosset-Yvrard, Thomas Seegmuller. Bubble on Real Estate: The Role of Altruism and Fiscal Policy. 2018. halshs-01880937

\section{HAL Id: halshs-01880937 https://shs.hal.science/halshs-01880937}

Preprint submitted on 25 Sep 2018

HAL is a multi-disciplinary open access archive for the deposit and dissemination of scientific research documents, whether they are published or not. The documents may come from teaching and research institutions in France or abroad, or from public or private research centers.
L'archive ouverte pluridisciplinaire HAL, est destinée au dépôt et à la diffusion de documents scientifiques de niveau recherche, publiés ou non, émanant des établissements d'enseignement et de recherche français ou étrangers, des laboratoires publics ou privés. 


\section{amse}

école d'économie d'aix-marseille

aix-marseille school of economics

\section{Working Papers / Documents de travail}

Bubble on Real Estate: The Role of Altruism and Fiscal Policy

Lise Clain-Chamosset-Yvrard

Thomas Seegmuller 


\title{
Bubble on real estate: The role of altruism and fiscal policy
}

\author{
Lise Clain-Chamosset-Yvrard*and Thomas Seegmuller ${ }^{\dagger \ddagger}$
}

\begin{abstract}
In this paper, we are interested in the interplay between real estate bubble, aggregate capital accumulation and taxation in an overlapping generations economy with altruistic households. We consider a three-period overlapping generations model with three key elements: altruism, portfolio choice, and financial market imperfections. Households realise different investment decisions in terms of asset at different periods of life, face a binding borrowing constraint and leave bequests to their children. We show that altruism plays a key role on the existence of a productive real estate bubble, i.e. a bubble in real estate raising physical capital stock and aggregate output. The key mechanism relies on the fact that a real estate bubble raises income of retired households. Because of higher bequests, there children are able to invest more in productive capital. Introducing fiscal policy, we show that raising real estate taxation dampens capital accumulation.
\end{abstract}

JEL classification: E22; E44; G11.

Keywords: Bubble; Altruism; Real estate; Credit; Overlapping generations.

\section{Introduction}

The question we address in this paper is how we can explain that a real estate bubble can enhance productive capital and therefore aggregate output, whereas we could have in mind that investments in productive capital and in real estate could rather be substitutable. This question is important regarding the consequences of the last financial crisis and also for the design of the fiscal policy. On the one hand, many countries have experienced real estate bubbles before the last financial crises and, at the same time, a rise in capital stocks and aggregate output. Some empirical studies

\footnotetext{
*Univ. Lyon, Université Lumière Lyon 2, GATE UMR 5824, F-69130 Ecully, France. E-mail: clainchamosset@gate.cnrs.fr

${ }^{\dagger}$ Corresponding author. Aix-Marseille University, CNRS, EHESS, Centrale Marseille, AMSE. E-mail: thomas.seegmuller@univ-amu.fr

${ }^{\ddagger}$ We are grateful for useful suggestions from Aurélien Eyquem, Frederic Jouneau-Sion, Xavier Raurich and Bertrand Wigniolle. We also thank participants to the Workshop "Macroeconomics, finance and history of economics" held on June 2017 at Ecully, to the conference SAET 2017 and to the workshop "Real and financial interdependencies: New approaches with dynamic general equilibrium models" held in Paris School of Economics on July 2017. Any remaining errors are ours. This work has benefited from the financial support of the French National Research Agency (ANR-15-CE33-0001-01).
} 
highlight that private non-residential investment in the United States increased significantly during the formation of the real estate bubble in the 2000s and then dropped when it burst (IMF, 2015). ${ }^{1}$ On the other hand, we note that the fiscal policy is especially designed to guide household savings. The french 2018 Finance Act (Loi de finances 2018), which replaces the solidarity tax on wealth by a tax on real estate wealth, is a perfect illustration. By concentrating taxes on real estate, considered as unproductive, a government aims to divert savings allocated from unproductive investment to productive one in order to promote economic growth. As wealth mainly consists in real estate for a large part of households, and most of them invest in real estate to leave an inheritance to their children, this idea that taxing real estate will necessarily promote productive capital could not hold for the whole economy.

The aim of this paper is to exhibit a mechanism through which a rational real estate bubble is accompanied by a boom in physical capital stock and in aggregate output. Our explanation is based on the altruistic behaviour of households. Our framework will be further used to study the macroeconomic consequences of real estate taxation.

We consider an overlapping generations model with three-period lived households. Households realise different investment decisions in terms of asset at different periods of life. When young, households can borrow and invest in real estate by buying land or a house for their old age. When middle-aged, they can save in the forms of deposits and physical capital to transfer wealth to their old age.

In our paper, there are three key elements. First, assets play different roles in our model. In addition to serve as a collateral, real estate allows young households to transfer resources to their old age. Accordingly, real estate can be seen as a long-term investment. Households behave as investors who buy a real estate asset for resale purpose only, and not for housing services. The real estate asset is intrinsically useless, meaning that its fundamental value is zero. This asset is a bubble when it has a positive value. Deposits and physical capital are both short-term investments. Indeed, households invest in these assets when middle-aged and receive returns when old. Nevertheless, deposits are the counterpart of loans and capital is used in production. This segmentation of asset markets reflects the idea that households first invest in real estate, kept during all the life-cycle and used to transfer bequests to children. Once this investment is reimbursed, agents are concerned with financial investments, through deposits and productive capital.

Second, we take into account financial market imperfections through a binding borrowing constraint faced by young households. This contrasts with most of the recent contributions in this literature, which focus on financial frictions at the entrepreneur level (among others, Farhi and Tirole, 2012; Martin and Ventura, 2012; Miao et al., 2015; Hirano and Yanagawa, 2017). In addition, some empirical studies support our assumption (see Campbell and Mankiw, 1989; Jappelli, 1990; Crook and Hochguertel, 2005). In our paper, households must pledge their labour income and their house as collaterals and, borrow against a part of their labour income and a part of the market value of their real estate asset. ${ }^{2}$ An increase in the market value of the real estate asset or a higher labour income help young households to relax their borrowing constraint. In this paper, labour income can be seen as a fundamental collateral and the real estate asset as a bubbly one. ${ }^{3}$

\footnotetext{
${ }^{1}$ In their papers, Kamihigashi (2008) and more recently Miao et al. (2017) provide some historical examples revealing that the bursting of a real estate bubble is often followed by a recession.

${ }^{2}$ On the one hand, empirical evidence confirms that real estate collateral plays a significant role during crisis (Mera and Renaud, 2000). Moreover, macroeconomics model dealing with financial frictions consider a real estate collateral constraint along the lines of Kiyotaki and Moore (1997) and Iacoviello (2005). On the other hand, some studies argue that the debt limit also depends on household income (Marcet and Singleton, 1991; Ludvigson, 1998).

${ }^{3}$ Martin and Ventura $(2011,2016)$ use a quite similar constraint except that the fundamental collateral corresponds
} 
The first type of collateral would rather represent the french system, while the second one would rather describe what happens in US. In addition, it will allow us to discuss the respective role of each type of collateral on the existence of a real estate bubble associated to a higher level of capital and output.

Third, households behave altruistically by leaving bequests to their children. Several empirical studies support the idea that households have a desire to leave bequests and, underline its importance for explaining saving behaviour (Kotlikoff and Summers, 1981; Dynan et al., 2004). In our model, the desire to leave bequests are rationalized by a family altruism, defined as the situation in which parents care about their children's income. As we will see, altruism is crucial for our results.

Our main concern is to investigate and understand the existence of a productive real estate bubble, i.e. a real estate bubble promoting capital accumulation and, thus aggregate output. We show that a real estate bubble occurs in a low interest rate environment. In this case, there exists an excess of savings in the economy, which provides a room for alternative stores of value. As the real estate bubble provides a return equal to one at the steady state, this return creates an incentive for households to hold the bubble and borrow to invest in this bubble.

Comparing the bubbleless and bubbly steady states, we show that a productive real estate bubble occurs when parents are sufficiently altruistic and the effects of fundamental and bubbly collaterals coming from the borrowing constraint are not too high. This result is consistent with empirical evidence showing that productive investment increases significantly during the formation of a bubble (Martin and Ventura, 2012). Altruism plays a key role on the occurrence of productive real estate bubbles. In an economy without altruism, middle-aged households have not a high enough income to sustain a higher level of capital in presence of a real estate bubble. Moreover, a productive real estate bubble exists whatever the type of collateral (fundamental or bubbly collateral) required by lender on the credit market. Surprisingly, the two types of collateral play quite similar roles and we cannot conclude that one type further promotes the emergence of real estate bubbles.

Finally, we also investigate the effect of fiscal policy on the stock of physical capital and, hence, on aggregate output. We show that an increase of a real estate tax has a negative effect on productive investment. An increase of the tax rate reduces the incentive to buy the real estate bubble, which reduces the income when old. It implies a negative effect on bequest distributed to middle-aged households, who invest less in physical capital. This result questions the view arguing that a government should increase taxation of unproductive assets, like real estate taxation, in order to boost productive investment and, thus aggregate output.

The paper proceeds as follows. In the next section, we discuss the related literature. Section 3 presents the model. Section 4 characterizes the co-existence of steady states without and with a real estate bubble and shows that the real estate bubble may enhance capital. Section 5 is devoted to the presentation of the model without altruism. Section 5 discusses the role of fiscal policy. A last section provides concluding remarks, whereas technical details are relegated to an Appendix.

\section{Related literature}

Our paper is related to a recent growing literature on rational housing bubbles in overlapping generations (OLG, henceforth) models. The existence of such bubbles has been studied in OLG models first by Arce and Lopez-Salido (2011) and Basco (2014). They investigate the interplay between real estate bubbles and financial frictions, but without physical capital accumulation in

to entrepreneur's income. 
contrast to our paper. In their models, households deriving utility from housing services, but they model the housing bubble as a shortage of assets in the economy, and not as a component of the housing price as in our model. By the way, Arce and Lopez-Salido (2011) show that the housing price is less than its fundamental value, i.e. the sum of discounted dividends, in the bubbly equilibrium. Zhao (2015) builds an OLG model with homeowners, who derive utility from housing services, and investors, who do not. He shows that a housing bubble only exists in an equilibrium in which investors hold houses for resale purpose only, and not for dividend purpose either in terms of rents or in terms of utility. In a recent contribution, Huber (2018) shows that an housing bubble, as a component of the housing price, can exist in an OLG economy with housing services, but without capital accumulation. Her results does not rely on the existence of any financial frictions, but on the features of the housing market. At each period, the young generation is endowed with a part of the housing stock belonging to the old generation. Through this feature, she introduces a new bubble at each period. In contrast to Zhao (2015) and Huber (2018), we abstract ourselves from modelling housing services through utility. This allows us to deeply focus on the the role of altruism in the existence of rational real estate bubble and on the interplay between rational real estate bubble and capital accumulation.

To the best of our knowledge, only Bosi et al. (2018) investigate the influence of altruism on the existence of a bubble. They consider a two-period OLG model with altruism and an asset bringing non-stationary positive dividends. They study the dynamics of capital stock and asset value. In contrast to our paper, they consider a form of altruism rationalized by a bequest constraint and are not concerned with the design of fiscal policy.

This paper also belongs to the rational bubble literature studying the macroeconomic effects of a bubble in OLG models with financial frictions. Farhi and Tirole (2012) and Martin and Ventura (2012) show that a bubble can have a crowd-in effect by promoting capital accumulation, and thus increasing aggregate output through the existence of financial frictions, which generates a wealth effect coming from the bubble. Even if we consider financial frictions, we differ from Martin and Ventura (2012) because our analysis does not require bubble shocks, and from Farhi and Tirole (2012) because our mechanism is not based on the existence of a wealth effect. It relies on the existence of altruistic households and, thus on inheritance. By receiving bequests, middle-aged households have a sufficiently high income to sustain a higher level of capital during bubbly episodes. Raurich and Seegmuller (2015) investigate the interplay between long-term productive investments in physical capital and short-term speculative ones in the asset bubble. Their mechanism is also different than ours, since it relies on selling short the bubble to invest more in capital. There is also a large literature studying the existence of productive bubbles in infinite horizon models which differs from our approach. For instance, Kocherlakota (2009), Hirano and Yanagawa (2017) and Miao and Wang (2018) build models with credit market imperfections. In contrast, Kamihigashi (2008) shows that bubbles can affect output positively in an economy with increasing social returns and capital spirit.

Finally, only few other contributions analyse the effects of taxation on both the existence of bubbles and on capital accumulation. Miao et al. (2015) are interested in the existence of a real estate bubble in an infinite-horizon model with production and credit constraints faced by the entrepreneurs. They show that a bubble can exist and reduce welfare. Some fiscal policies, such as property or transaction taxation, are able to eliminate the bubble. We differ from this paper since we consider a model with altruistic households facing credit constraints. Furthermore, we address a different political issue. Raurich and Seegmuller $(2015,2017)$ also deal with fiscal policy issue, by analysing the consequences of capital and labour income taxes on the existence and macroeconomic 
effect of a bubble. In our paper, we consider an alternative source of taxation, namely a real estate taxation.

\section{Model}

We consider an overlapping generations model with discrete time $(t=0,1, \ldots,+\infty)$. This economy consists of two types of agents, households and firms.

\subsection{Households}

There is no population growth and, at each date $t$, a generation of unit size is born. Each generation lives for three periods.

Utility. Preferences are represented by an additively separable life-cycle utility function:

$$
\ln c_{1, t}+\beta \ln c_{2, t+1}+\beta^{2} \ln c_{3, t+2}+\delta \epsilon \ln \left(\phi w_{t+2}+x_{t+2}\right)
$$

where $c_{1, t}, c_{2 t+1}$, and $c_{3, t+2}$ denote the consumption at time $t, t+1, t+2$ of a household born at $t, \beta \in(0,1)$ the discount factor and $\delta>0$ the degree of altruism of a household. The parameter $\epsilon \in\{0,1\}$ allows us to consider the model with or without altruism.

Through these preferences, we introduce family altruism, defined as the situation in which generation $t$ cares about the next generation income. More precisely, old parents take care about their middle-aged children: $\phi w_{t+2}$ represents the labour income of a middle-aged agent born at time $t+1$ and $x_{t+2}$ her bequest received from their old parents born at time $t$.

Budget constraints. In her first period of life, the household is young and supplies one unit of labour inelastically remunerated at the wage $w_{t}$. She can borrow an amount $d_{t}^{y}$ on a credit market. With her wage and borrowing, she can consume an amount $c_{1, t}$ of final good and buy an asset $h_{t+1}$, which is assumed to be intrinsically useless, at the price $p_{t}$ in units of consumption. We interpret this asset as real estate. A positive price $p_{t}>0$ depicts a bubble on real estate.

At the second period of life, the household is middle-aged. Having a better productivity, she supplies inelastically $\phi$ efficient units of labour remunerated at the wage $w_{t+1}$. A middle-aged household may receive a bequest $x_{t+1}$ from their old parents. Bequests and labour income are used to repay their debt at the gross rate $R_{t+1}^{d}$, to consume $c_{2, t+1}$ of final good, and to save through a diversified portfolio of physical capital $k_{t+2}$ and deposits $d_{t+1}^{m}$.

At the third period of life, the household is old and retired. She uses the sales of their real estate asset bought at time $t$ at price $p_{t+2}$ and her remunerated savings from physical capital at the gross rate $R_{t+2}$ and from her deposit at the gross rate $R_{t+2}^{d}$ to consume $c_{3, t+2}$ units of final good and give a positive bequest $x_{t+2}$ to her children. ${ }^{4}$

$$
\begin{aligned}
c_{1, t}+p_{t} h_{t+1} & =w_{t}+d_{t}^{y} \\
c_{2, t+1}+R_{t+1}^{d} d_{t}^{y}+d_{t+1}^{m}+k_{t+2} & =\phi w_{t+1}+\epsilon x_{t+1} \\
c_{3, t+2}+\epsilon x_{t+2} & =p_{t+2} h_{t+1}+R_{t+2} k_{t+2}+R_{t+2}^{d} d_{t+1}^{m} \\
x_{t+2} & \geqslant 0
\end{aligned}
$$

\footnotetext{
${ }^{4}$ We assume a full capital depreciation within a period.
} 
Through these budget constraints, we assume that a household chooses first to invest in a long term asset, real estate, that she resells when hold, and has access to the productive capital only at middle-age. Interpreting $k_{t+2}$ as shares of firms, it symbolizes the idea that households first invest in real estate, kept during all the life-cycle and used to transfer bequests to children. The loans to finance this investment are reimbursed in middle-age. Then, agents are concerned with financial investments, through deposits and productive capital.

Borrowing constraint. Doing their investment in real estate, young households face a borrowing constraint:

$$
\begin{aligned}
R_{t+1}^{d} d_{t}^{y} & \leq \theta_{1} p_{t+1} h_{t+1}+\theta_{2} \phi w_{t+1} \\
\text { with } 0 & \leq \theta_{1}<1 \text { and } 0 \leq \theta_{2}<1
\end{aligned}
$$

Borrowing can only take place up to the point where the principal plus interest, i.e. $R_{t+1}^{d} d_{t}^{y}$, is secured by a fraction $\theta_{1}$ of the market value of real estate owned by the household at $t+1$, and a fraction $\theta_{2}$ of her wage received at the period of debt repayment. If households repudiate their loan obligations, the lenders can seize a fraction $\theta_{1}$ of their real estate asset. This collateral constraint is consistent with standard lending criteria used in the mortgage market. This type of constraint generates two wealth effects one which is direct coming from future wage, and the other one which is indirect by modifying the relative price of the asset used as collateral. Through this constraint, we make a distinction between a "fundamental" collateral (future wages) and a "bubbly" collateral (value of bubble asset).

Optimal behaviour. Let us assume $\epsilon=1$, i.e. agents are altruistic. A household derives her optimal consumption choice $\left(c_{1, t}, c_{2, t+1}, c_{3, t+2}\right)$, her optimal portfolio choice $\left(k_{t+2}, d_{t}^{y}, d_{t+1}^{m}, h_{t+1}\right)$, and her optimal bequest $\left(x_{t+2}\right)$ by maximizing her utility function (1) under her budget, bequest and borrowing constraints (2)-(6). We restrict our attention to an economy in which the borrowing constraint is binding. The optimal behaviour of a household born at time $t$ is summarized by the following equations (see also Appendix 8.1):

$$
\begin{aligned}
\frac{\beta^{2}}{c_{3, t+2}}\left(p_{t+2}-\theta_{1} p_{t+1} R_{t+2}\right) & =\frac{1}{c_{1, t}}\left(p_{t}-\theta_{1} \frac{p_{t+1}}{R_{t+1}}\right) \\
\frac{1}{c_{2, t+1}} & =R_{t+2} \frac{\beta}{c_{3, t+2}} \\
R_{t+2}^{d} & =R_{t+2} \\
\frac{\beta^{2}}{c_{3, t+2}} & =\frac{\delta}{\phi w_{t+2}+x_{t+2}} \\
\theta_{1} p_{t+1} h_{t+1}+\theta_{2} \phi w_{t+1} & =R_{t+1} d_{t}^{y} \\
\beta^{2} R_{t+1}^{d} R_{t+2} c_{1, t} & <c_{3, t+2} \\
x_{t+2} & >0
\end{aligned}
$$

Because of the borrowing constraint, Eq. (7) depicts a modified intertemporal trade-off between the first and third period consumptions. It requires that the following inequality must be satisfied at each period $t$ :

$$
\theta_{1} \frac{p_{t+1}}{p_{t}}<R_{t+1}<\frac{1}{\theta_{1}} \frac{p_{t+1}}{p_{t}}
$$


Since households face no borrowing constraints at their second and third period of life, Eq. (8) depicts the standard intertemporal trade-off between the second and third period consumptions. In their second period of life, households save through a diversified portfolio of deposits and physical capital. As the two assets are perfectly substitutes, they should provide the same return (Eq. (9)). Eq. (10) depicts the trade-off between the strictly positive bequests and third-period consumption. Since we restrict our attention to an economy with a binding borrowing constraint (Eq. (11)), inequality (12) should be satisfied.

\subsection{Firms}

The technology is characterized by the following aggregate production function:

$$
Y_{t}=K_{t}^{\alpha} L_{t}^{1-\alpha} \text {, with } \alpha \in(0,1 / 2)
$$

where $L_{t}$ is the total amount of efficient units of labour and $K_{t}$ is the stock of physical capital in the economy. Using $a=K / L$, the intensive production function is $Y_{t} / L_{t}=a_{t}^{\alpha}$, and competitive factor prices are given by :

$$
\begin{aligned}
& w_{t}=(1-\alpha) a_{t}^{\alpha} \equiv w\left(a_{t}\right) \\
& R_{t}=\alpha a_{t}^{\alpha-1} \equiv R\left(a_{t}\right)
\end{aligned}
$$

Let $s \equiv(1-\alpha) / \alpha(>1)$. Using Eqs. (16) and (17), we obtain the ratio of factor prices:

$$
\frac{w_{t}}{R_{t}}=s a_{t}
$$

\subsection{Asset markets}

The market of real estate asset is segmented in the sense that only young and old households can trade this asset $h_{t}$. As already explained, young households buy the asset in order to sell it when they will be old. Households behave as investors who buy real estate for resale purpose only, and not for housing services. ${ }^{5}$ The supply of this asset is fixed and normalized to 2 . Since this asset has no fundamental value, a bubble exists if $p_{t}>0$.

Deposits from middle-aged are used for loans of the young. This explains that loans and deposits provide the same rate $R_{t+1}^{d}$.

\subsection{Intertemporal equilibrium}

At date $t=0$, the initial old household and initial middle-aged household hold one unit of real estate. Therefore, at each period, only one unit of financial asset is exchanged, implying that $h_{t+1}=1$. Loans being equal to deposits, at each period of time, we have $d_{t}^{y}=d_{t}^{m} \equiv d_{t}$.

\footnotetext{
${ }^{5}$ In an OLG model with households deriving utility from housing services (homeowners) and others doing not (investors), Zhao (2015) shows that a bubble in house price exists in an equilibrium if investors hold houses for resale purpose only and not for dividend purpose either in terms of rents or in terms of utility. Based on this result, we do not model the behaviour of an homeowner. This allows us to focus on the the role of altruism in the existence of asset bubble. Arce and Lopez-Salido (2011) and Basco (2014) also study housing bubbles in overlapping generations models. Nevertheless, they model housing bubble as a shortage of assets in the economy, and not as a component of the housing price.
} 
Taking into account that the population size of a generation is normalized to one, labor measured in efficient units is equal to $L_{t}=1+\phi$. Then, equilibrium on the physical capital market means that capital per capita is given by $k_{t}=(1+\phi) a_{t}$. In addition, since physical capital and deposits are perfect substitutes for a household, they provide the same return at the equilibrium, i.e. $R_{t}=R_{t}^{d}$.

Using Eq. (18), we deduce that Eq. (11) rewrites as:

$$
d_{t}=\frac{\theta_{1} p_{t+1}}{R_{t+1}}+\theta_{2} \phi s a_{t+1}
$$

Then, using the above equilibrium conditions, the budget constraints (2)-(4), Eqs. (16) and (19), the trade-offs (7), (8) and (10) write:

$$
\begin{aligned}
\left(\theta_{1} \frac{p_{t+1}}{R_{t+1}}-p_{t}\right)\left(\phi s R_{t+2} a_{t+2}+x_{t+2}\right)= & \delta\left(\theta_{1} p_{t+1} R_{t+2}-p_{t+2}\right)\left(s R_{t} a_{t}+\theta_{2} \phi s a_{t+1}+\theta_{1} \frac{p_{t+1}}{R_{t+1}}-p_{t}\right) \\
\beta\left(\phi s R_{t+2} a_{t+2}+x_{t+2}\right)= & \delta R_{t+2}\left[\phi s R_{t+1} a_{t+1}\left(1-\theta_{2}\right)-\left(1+\phi+\phi \theta_{2} s\right) a_{t+2}\right. \\
& \left.+x_{t+1}-\theta_{1}\left(p_{t+1}+\frac{p_{t+2}}{R_{t+2}}\right)\right] \\
\frac{\beta^{2}}{\delta}\left(\phi s R_{t+2} a_{t+2}+x_{t+2}\right)= & \left(1+\theta_{1}\right) p_{t+2}+\left(1+\phi+\theta_{2} \phi s\right) R_{t+2} a_{t+2}-x_{t+2}
\end{aligned}
$$

From Eq. (22), we deduce:

$$
x_{t+2}=\delta \frac{\left(1+\theta_{1}\right) p_{t+2}+\left[1+\phi+\left(\theta_{2}-\beta^{2} / \delta\right) \phi s\right] R_{t+2} a_{t+2}}{\beta^{2}+\delta}
$$

Let us consider the following assumption:

Assumption $1 \delta>\underline{\delta}$, with $\underline{\delta} \equiv \beta^{2} \frac{\phi s}{1+\phi+\phi \theta_{2} s}$.

Assumption 1 ensures a strictly non-negative bequests, i.e. $x_{t+2}>0$, by imposing a sufficiently a degree of altruism $\delta$. Substituting the expression of $x_{t}$ defined by Eq. (23) into Eqs. (20) and (21), the intertemporal trade-offs faced by households are summarized by the following equations:

$$
\begin{aligned}
\left(\theta_{1} \frac{p_{t+1}}{R_{t+1}}-p_{t}\right)\left(A_{1} R_{t+2} a_{t+2}+A_{2} p_{t+2}\right) & =\left(\theta_{1} p_{t+1} R_{t+2}-p_{t+2}\right)\left(s R_{t} a_{t}+A_{3} a_{t+1}+\theta_{1} \frac{p_{t+1}}{R_{t+1}}-p_{t}\right) \\
B_{1} p_{t+2} & =R_{t+2}\left(B_{2} R_{t+1} a_{t+1}-B_{3} p_{t+1}-B_{4} a_{t+2}\right)
\end{aligned}
$$

with

$$
\begin{aligned}
& A_{1} \equiv\left[1+\phi+\left(1+\theta_{2}\right) \phi s\right] /\left(\beta^{2}+\delta\right)>0 \\
& A_{2} \equiv\left(1+\theta_{1}\right) /\left(\beta^{2}+\delta\right)>0 \\
& A_{3} \equiv \theta_{2} \phi s>0 \\
& B_{1} \equiv \theta_{1}+\left(1+\theta_{1}\right) \beta /\left(\beta^{2}+\delta\right)>0 \\
& B_{2} \equiv\left[\delta(1+\phi)+\left(\delta-\theta_{2} \beta^{2}\right) \phi s\right] /\left(\beta^{2}+\delta\right)>0 \\
& B_{3} \equiv\left(\beta^{2} \theta_{1}-\delta\right) /\left(\beta^{2}+\delta\right) \\
& B_{4} \equiv\left(1+\phi+\theta_{2} \phi s\right)\left(\beta+\beta^{2}+\delta\right) /\left(\beta^{2}+\delta\right)+\beta \phi s /\left(\beta^{2}+\delta\right)>0
\end{aligned}
$$

and $R_{t+1}$ given by Eq. (17). 
Definition 1 Under Assumption 1, an intertemporal equilibrium with perfect foresight is a sequence $\left(a_{t}, p_{t}\right) \in \mathbb{R}_{++} \times \mathbb{R}_{+}, t=0,1, \ldots,+\infty$, such that the dynamic system (24)-(25) is satisfied, the borrowing constraint is binding and $\theta_{1} \frac{p_{t+1}}{p_{t}}<R_{t+1}<\frac{1}{\theta_{1}} \frac{p_{t+1}}{p_{t}}$, where $R_{t+1}$ is defined by Eq. (17) and $a_{0}>0$ is given.

In the following, we will use the definition of the equilibrium to analyse the existence of a steady state with a productive real estate bubble, i.e. a bubble associated to a larger level of capital and output per worker. ${ }^{6}$

\section{Is the real estate bubble capital enhancing?}

From Eq. (24), there exist two types of steady states: a bubbleless steady state (i.e. $p=0$ ) and a bubbly steady state (i.e. $p>0$ ). We first characterize the bubbeless steady state, and second the bubbly. Then, we will be able to compare them to show that the bubble may enhance capital.

\subsection{Bubbleless steady state $p=0$}

A bubbleless steady state is characterized by $\underline{p}=0$. Using (25), the gross interest rate $\underline{R}$ and the capital per labour $\underline{a}$ are respectively given by:

$$
\underline{R}=\frac{B_{4}}{B_{2}} \text { and } \underline{a}=\left(\alpha \frac{B_{2}}{B_{4}}\right)^{1 /(1-\alpha)}
$$

Note that Assumption 1 ensures a non-negative gross interest rate, i.e. $\underline{R}>0$.

Proposition 1 Let $\hat{\delta} \equiv \beta\left[\left(1+\phi+\phi \theta_{2} s\right)(1+\beta)+\phi s\left(1+\theta_{2} \beta\right)\right] /\left[\phi s\left(1-\theta_{2}\right)\right]$. Under Assumption 1 , there exist $\underline{\phi}$ and $\bar{\theta}_{2}>0$ such that there is a unique bubbleless steady state $(\underline{p}, \underline{R})$ with a binding borrowing constraint characterized by $\underline{p}=0$ and $\underline{R} \in(0,1)$ if $\delta$ is sufficiently high such that $\delta>\hat{\delta}$, $\phi>\underline{\phi}$ and $\theta_{2}<\bar{\theta}_{2}$.

Proof. See Appendix 8.2.

To understand that $\underline{R}<1$ is obtained, let us recall that only middle-aged households can invest in physical capital. If households are sufficiently altruistic, then they will leave a high amount of bequest to their middle-aged children, ceteris paribus. As savings are normal good, middle-aged households can save a significant amount in physical capital for a given wage $w$. This tends to lower the interest rate. If household cannot pledge a huge part of their income (weak $\theta_{2}$ ), the loan repayment will be weak. For a given wage $w$, their income after loan repayment will be high, thus middle-aged household will increase their savings in physical capital, ceteris paribus. This tends to lower the interest rate. We finally note that a high enough $\phi$ means that labour income is more redistributed to middle-aged. This facilitates a positive borrowing for the young agents, through the redistribution of income from the middle-age to the young.

\footnotetext{
${ }^{6}$ Since the economy is described by a four-dimensional dynamic system, we restrict our attention to the analysis of steady states and do not study the dynamics.
} 


\subsection{Bubbly steady state $p>0$}

A bubbly steady state $(\bar{p}, \bar{R}, \bar{a})$ must satisfy the following system:

$$
\begin{aligned}
&\left\{\begin{array}{l}
G(\bar{R})=H(\bar{R}) \\
\bar{p}=\bar{R} G(\bar{R}) \bar{a}
\end{array}\right. \\
& \text { with } G(R) \equiv B_{2} \frac{R-\underline{R}}{B_{1}+R B_{3}} \\
& \text { and } H(R) \equiv \frac{-\left(R-\theta_{1}\right) A_{1}+\left(1-\theta_{1} R\right)\left(s R+A_{3}\right)}{\left(R-\theta_{1}\right)\left(A_{2}+1-\theta_{1} R\right)} \\
& \text { where } R \equiv R(a) \text { is given by Eq. }(17) .
\end{aligned}
$$

The borrowing constraint is binding if Inequality (12) is satisfied. Combining with Eq. (7), a binding borrowing constraint implies $\bar{R}<1$ at the steady state. Moreover, Inequality (14) must be satisfied at the steady state. Therefore, at the bubbly steady state, $\bar{R}$ must belong to $\left(\theta_{1}, 1\right)$.

According to the sign of $B_{3}$, two types of bubbly steady states can exist: a steady state with unproductive real estate bubble $(\underline{R}<\bar{R}$ or $\bar{a}<\underline{a})$ and a steady state with productive real estate bubble $(\underline{R}>\bar{R}$ or $\underline{a}<\bar{a})$. Note that the steady state with productive real estate bubble could occur only if $B_{3}<0$ and $\bar{R}>-B_{1} / B_{3}>\theta_{1} \cdot{ }^{7}$ As a steady state with productive real estate bubble is in accordance with the data, we will restrict our attention to the case for which $\bar{R}>-B_{1} / B_{3}$. To ensure $B_{3}<0$, we make the following assumption:

Assumption $2 \delta>\bar{\delta}$, with $\bar{\delta} \equiv \beta^{2} \theta_{1}$.

Taking into account that there is a bubbleless steady state, we show the existence of a bubbly steady state with a higher level of production:

Proposition 2 Let $\bar{\theta}_{1} \equiv\left(1+\phi+\phi \theta_{2} s\right) /(1+\phi+\phi s)$. Under Assumptions 1 and 2 , there exists $\tilde{\delta}>0$ such that a unique steady state with productive real estate bubble $(\bar{a}, \bar{p})$ characterized by $\bar{R} \in\left(-B_{1} / B_{3}, \underline{R}\right)$ and $\bar{p}>0$ coexists with the bubbleless steady state if $\phi$ is close to but larger than $\underline{\phi}, \theta_{2}<\bar{\theta}_{2}, \theta_{1}<\bar{\theta}_{1}$ and $\delta$ sufficiently high such that $\delta>\max \{\tilde{\delta}, \bar{\delta}, \widehat{\delta}\}$. This means that $\bar{a}>\underline{a}$.

Proof. See Appendix 8.3.

We show that the real estate bubble is productive and the bubbly steady state coexists with the bubbleless one if $\underline{R}<1$. A low interest rate environment means that there is an excess of savings in the economy without bubble, which provides a room for alternative stores of value. At the bubbly steady state, the real estate bubble provides a higher return equal to one. Therefore, this return creates an incentive for households to hold the bubble, since other assets have lower returns and borrowing has a lower cost.

We also observe that, according to Proposition 2, a productive real estate bubble occurs if households are sufficiently altruistic (i.e. high $\delta$ ), the effects of fundamental and bubbly collaterals are positive but not too important (i.e. $\theta_{2}<\bar{\theta}_{2}$ and $\theta_{1}<\bar{\theta}_{1}$ ), and an important share of labor income is distributed to middle-aged agents (i.e. $\phi$ high enough).

\footnotetext{
${ }^{7}$ According to (27), a stationary bubble means $G(\bar{R})>0$.
} 
To understand the main mechanisms explaining that a real estate bubble enhances capital, we rewrite the first and second period budget constraints combined with the borrowing constraint at the bubbly steady state:

$$
\begin{aligned}
c_{1}+p\left(1-\theta_{1} / R\right) & =w\left(1+\phi \theta_{2} / R\right) \\
c_{2}+\frac{1+R}{R}\left(\theta_{1} p+\theta_{2} \phi w\right)+(1+\phi) a & =\phi w+x
\end{aligned}
$$

A sufficiently altruistic household want to leave high bequests to their middle-aged children. Investing in the real estate bubble when young and reselling it when old allows her to increase bequests, which pushes up the income of their children at middle-age. This additional income is in particular used to raise the investment in capital, which explains that the real estate bubble is productive.

We deduce from Proposition 2 that a real estate bubble is productive under quite similar conditions on $\theta_{1}$ and $\theta_{2}$. This suggests that fundamental and bubbly collaterals play similar roles on the existence of the real estate bubble, even if the interpretations can be slightly different. By inspection of Eq. (30), higher $\theta_{1}$ and $\theta_{2}$ increase the role of collateral and allow the household to borrow more when young. Indeed, taking into account the credit constraint, a higher $\theta_{2}$ generates a positive income effect through the wage, whereas a higher $\theta_{1}$ implies a lower price of the real estate bubble. Both these effects will promote a higher price of the real estate asset, which increases wealth when old, bequests and therefore investment in capital of the middle-aged households. However, using Eq. (31), we observe that at middle-age, a higher $\theta_{1}$ or $\theta_{2}$ means a higher debt reimbursed and a larger funding of the borrowing of young agents. Both these effects have a negative impact on capital accumulation and explain that our result does not hold when either $\theta_{1}$ or $\theta_{2}$ is too close to one.

We finally note that a high enough value of $\phi$ contributes to ensure a significant income at middle-age to finance investments and the reimbursement of the loans contracted while being young.

Of course, the most important ingredient for our explanation of productive real estate bubble lies on altruism. The sufficient conditions we get are based on a sufficiently high degree of altruism. To clarify the crucial role played by altruism to generate a real estate bubble which enhances capital, we analyse now the model without altruism and show that the bubble crowds out capital instead of raising it.

\section{The crucial role of altruism}

The model without altruism corresponds to the case where $\epsilon=0$. Its analysis is quite similar to the model with altruism. Therefore, for the sake of brevity, we present the main derivations only.

A household maximizes the utility (1) under the budget constraints (2)-(4) and the borrowing constraint (6). Focusing on solutions with a binding borrowing constraint, we get the following 
optimal conditions:

$$
\begin{aligned}
\frac{\beta^{2}}{c_{3, t+2}}\left(p_{t+2}-\theta_{1} p_{t+1} R_{t+2}\right) & =\frac{1}{c_{1, t}}\left(p_{t}-\theta_{1} \frac{p_{t+1}}{R_{t+1}}\right) \\
\frac{1}{c_{2, t+1}} & =R_{t+2} \frac{\beta}{c_{3, t+2}} \\
R_{t+2}^{d} & =R_{t+2} \\
\theta_{1} p_{t+1} h_{t+1}+\theta_{2} \phi w_{t+1} & =R_{t+1} d_{t}^{y} \\
\beta^{2} R_{t+1}^{d} R_{t+2} c_{1, t} & <c_{3, t+2}
\end{aligned}
$$

We still need to have $\theta_{1} \frac{p_{t+1}}{p_{t}}<R_{t+1}<\frac{1}{\theta_{1}} \frac{p_{t+1}}{p_{t}}$. An equilibrium satisfies $h_{t}=1, k_{t}=(1+\phi) a_{t}$, $d_{t}^{y}=d_{t}^{m}=d_{t}$. Using Eqs. (2)-(4), (6) and the trade-offs (32) and (33), we get:

$$
\begin{aligned}
& p_{t+2}\left(1+\theta_{1}\right)+R_{t+2} a_{t+2}\left(1+\phi+\phi \theta_{2} s\right)=\beta R_{t+2}\left[\phi s R_{t+1} a_{t+1}\left(1-\theta_{2}\right)\right. \\
& \left.-\left(1+\phi+\phi \theta_{2} s\right) a_{t+2}-\theta_{1}\left(p_{t+1}+\frac{p_{t+2}}{R_{t+2}}\right)\right] \\
& \left(p_{t}-\theta_{1} \frac{p_{t+1}}{R_{t+1}}\right)\left[p_{t+2}\left(1+\theta_{1}\right)+R_{t+2} a_{t+2}\left(1+\phi+\phi \theta_{2} s\right)\right]=\beta^{2}\left(p_{t+2}-\theta_{1} p_{t+1} R_{t+2}\right) \\
& \left(s R_{t} a_{t}+\theta_{2} \phi s a_{t+1}+\theta_{1} \frac{p_{t+1}}{R_{t+1}}-p_{t}\right)
\end{aligned}
$$

and the condition for a binding borrowing constraint rewrites:

$$
p_{t+2}\left(1+\theta_{1}\right)+R_{t+2} a_{t+2}\left(1+\phi+\phi \theta_{2} s\right)>\beta^{2} R_{t+1} R_{t+2}\left(s R_{t} a_{t}+\theta_{2} \phi s a_{t+1}+\theta_{1} \frac{p_{t+1}}{R_{t+1}}-p_{t}\right)
$$

A bubbleless steady state with selfish households $\left(\underline{p}_{s}, \underline{R}_{s}\right)$ is characterized by $\underline{p}_{s}=0$. Using (37), the gross interest rate $\underline{R}_{s}$ is given by:

$$
\underline{R}_{s}=\frac{1+\beta}{\beta} \frac{1+\phi+\theta_{2} \phi s}{\left(1-\theta_{2}\right) \phi s}
$$

Moreover, using (39), the borrowing constraint is binding if and only if $F_{s}(\phi)>0$, with:

$$
F_{s}(\phi) \equiv\left(1-\theta_{2}\right)^{2} s \phi^{2}-(1+\beta)\left[1+\beta+\phi\left(1+\beta+\theta_{2} s(1+2 \beta)\right)\right]
$$

We can easily see that $F_{s}(0)<0$ and $F_{s}(+\infty)=+\infty$. Therefore, there exists $\underline{\phi}_{s}>0$ such that $F_{s}(\phi)>0$ for all $\phi>\underline{\phi}_{s}$.

Proposition 3 There exists $\underline{\phi}_{s}>0$ such that there is a unique bubbleless steady state $\underline{R}_{s}$ with selfish households with a binding borrowing constraint if $\phi>\underline{\phi}_{s}$.

Let us focus now on a bubbly steady state with selfish households $\left(\bar{p}_{s}, \bar{R}_{s}, \bar{a}_{s}\right)$. Using Eqs. $(37)$ and (38), it satisfies:

$$
\frac{\bar{p}_{s}}{\bar{R}_{s} \bar{a}_{s}}=G_{0}\left(\bar{R}_{s}\right)=H_{0}\left(\bar{R}_{s}\right)
$$




$$
\begin{aligned}
\text { with } G_{0}(R) & \equiv \beta \phi s\left(1-\theta_{2}\right) \frac{R-\underline{R}_{s}}{1+\theta_{1}(1+\beta)+\theta_{1} \beta R} \\
\text { and } H_{0}(R) & \equiv \frac{\beta^{2}\left(1-\theta_{1} R\right)\left(s R+\theta_{2} \phi s\right)-\left(R-\theta_{1}\right)\left(1+\phi+\phi \theta_{2} s\right)}{\left(R-\theta_{1}\right)\left(1+\theta_{1}+\beta^{2}-\beta^{2} \theta_{1} R\right)}
\end{aligned}
$$

We immediately see that $\bar{p}_{s}>0$ means that $G_{0}\left(\bar{R}_{s}\right)>0$, which implies that $\bar{R}_{s}>\underline{R}_{s}$.

Proposition 4 Every bubbly steady state $\bar{R}_{s}$ with selfish households with a binding borrowing constraint is characterized by $\bar{R}_{s}>\underline{R}_{s}$. This means that without altruism, a stationary real estate bubble can never be productive.

This result confirms that altruism plays a key role for the occurrence of productive real estate bubbles. In the absence of altruism and bequest, middle-aged households have not a high enough income to sustain a higher level of capital when there is a real estate bubble.

\section{Real estate taxation}

There is a recurrent debate discussing whether it is better to tax real estate rather than capital to accumulate more productive assets (see Leung, 2004). Using our model, we provide an argument showing that a higher tax on real estate diminishes capital. Therefore, it is not clear cut that one should recommend higher taxes on real estate.

We extend the model with altruism to take into account a tax on real estate. The main idea is to discuss whether a higher tax on real estate does or not generate a higher level of capital. Accordingly, we introduce a proportional tax on real estate $\tau_{h}(<1)$, paid by the consumer when old. Despite the fact that it distorts the relative prices, this tax is used to finance a public good that affects neither the preferences, nor the production.

With these new ingredients, the budget constraints (2)-(4) write:

$$
\begin{aligned}
c_{1, t}+p_{t} h_{t+1} & =w_{t}+d_{t}^{y} \\
c_{2, t+1}+R_{t+1}^{d} d_{t}^{y}+d_{t+1}^{m}+k_{t+2} & =\phi w_{t+1}+x_{t+1} \\
c_{3, t+2}+x_{t+2} & =\left(1-\tau_{h}\right) p_{t+2} h_{t+1}+R_{t+2} k_{t+2}+R_{t+2}^{d} d_{t+1}^{m}
\end{aligned}
$$

while the utility is still given by (1) with $\epsilon=1$.

There is a government that uses the tax revenues to finance government spendings $G_{t}$ according to the following balanced budget:

$$
G_{t}=\tau_{h} p_{t} h_{t-1}
$$

Since the tax rate $\tau_{h}$ is constant, public spendings $G_{t}$ vary to balance the budget at each period of time.

The rest of the model is similar to the one without taxation. Therefore, households maximize utility (1) under the budget constraints (45)-(47) and the borrowing constraint (6). The optimal behaviour of a household is solved in Appendix 8.4. By continuity with respect to the case without taxation, the following inequalities should be satisfied:

$$
\theta_{1} \frac{p_{t+1}}{p_{t}}<R_{t+1}<\frac{1}{\theta_{1}}\left(1-\tau_{h}\right) \frac{p_{t+1}}{p_{t}}
$$


As in Section 2.5, an equilibrium satisfies $h_{t}=1, k_{t}=(1+\phi) a_{t}$ and $d_{t}^{y}=d_{t}^{m}=d_{t}$. Using Eq. (47) and $\beta^{2}\left(\phi w_{t+2}+x_{t+2}\right)=\delta c_{3, t+2}$, we deduce that:

$$
x_{t+2}=\delta \frac{\left(1-\tau_{h}+\theta_{1}\right) p_{t+2}+\left[1+\phi+\left(\theta_{2}-\beta^{2} / \delta\right) \phi s\right] R_{t+2} a_{t+2}}{\beta^{2}+\delta}
$$

Under Assumption 1, the bequest is positive whatever the tax rate and the bubble are. Following the same methodology than in Section 2.5, an equilibrium is defined by the following two equations:

$$
\begin{aligned}
{\left[p_{t}-\theta_{1} \frac{p_{t+1}}{R_{t+1}}\right]\left(A_{1} R_{t+2} a_{t+2}+\tilde{A}_{2} p_{t+2}\right)=} & {\left[\left(1-\tau_{h}\right) p_{t+2}-\theta_{1} p_{t+1} R_{t+2}\right] } \\
& \left(s R_{t} a_{t}+A_{3} a_{t+1}+\theta_{1} \frac{p_{t+1}}{R_{t+1}}-p_{t}\right) \\
p_{t+2} \tilde{B}_{1}= & R_{t+2}\left(B_{2} R_{t+1} a_{t+1}-\tilde{B}_{3} p_{t+1}-B_{4} a_{t+2}\right)
\end{aligned}
$$

with

$$
\tilde{A}_{2} \equiv \frac{1-\tau_{h}+\theta_{1}}{\beta^{2}+\delta}, \tilde{B}_{1} \equiv \beta \frac{1-\tau_{h}+\theta_{1}}{\beta^{2}+\delta}+\theta_{1}, \tilde{B}_{3} \equiv \frac{\beta^{2} \theta_{1}-\delta\left(1-\tau_{h}\right)}{\beta^{2}+\delta}
$$

and $A_{1}, A_{3}, B_{2}$ and $B_{4}$ defined as in Section 2.5.

Of course, a bubbleless steady state is not affected by the real estate tax rate $\tau_{h}$. In contrast, a bubbly steady state with taxation $\left(\bar{p}_{T}, \bar{R}_{T}, \bar{a}_{T}\right)$ must satisfy the following system which depends on $\tau_{h}$ :

$$
\begin{aligned}
\frac{\bar{p}_{T}}{\bar{R}_{T} \bar{a}_{T}} & =G_{T}\left(\bar{R}_{T}\right)=H_{T}\left(\bar{R}_{T}\right) \\
\text { with } G_{T}(R) & \equiv B_{2} \frac{R-\underline{R}_{T}}{\tilde{B}_{1}+R \tilde{B}_{3}} \\
\text { and } H_{T}(R) & \equiv \frac{\left(1-\tau_{h}-\theta_{1} R\right)\left(s R+A_{3}\right)-\left(R-\theta_{1}\right) A_{1}}{\left(R-\theta_{1}\right)\left(\tilde{A}_{2}+1-\tau_{h}-\theta_{1} R\right)}
\end{aligned}
$$

The borrowing constraint is binding at the bubbly steady state with taxation if $\bar{R}_{T}<\sqrt{1-\tau_{h}}$. Moreover, Inequality (49) must be satisfied at the steady state, i.e. $\theta_{1}<\bar{R}_{T}<\left(1-\tau_{h}\right) / \theta_{1}$.

At this stage, we consider that there exists a bubbly steady state with taxation $\bar{R}_{T} \in\left(-\tilde{B}_{1} / \tilde{B}_{3}, \underline{R}_{T}\right)$ whose existence and uniqueness are shown in a similar way than in Proposition $2 .{ }^{9}$ We investigate the effect of taxes on such an equilibrium. The role of the tax on real estate $\tau_{h}$ is summarized in the following proposition:

Proposition 5 Under Assumption 1, consider that there exists a unique bubbly steady state with taxation $\bar{R}_{T}$ and a binding borrowing constraint. Assuming $\delta>\beta / \theta_{1}$, we show that $\bar{R}_{T}$ is increasing in $\tau_{h}$, meaning that $\bar{a}_{T}$ is decreasing in $\tau_{h}$.

Proof. See Appendix 8.5.

${ }^{8}$ Using Appendix 8.4, the borrowing constraint is binding combining Inequality (90) and Eq. (85).

${ }^{9}$ Of course, by continuity, this is obvious if the tax rate is low enough. 
This proposition shows that an increase of the tax on real estate has a negative effect on investment in productive capital. An increase of $\tau_{h}$ reduces the incentive to buy the real estate bubble, which reduces the income when old. Thus, it has a negative effect on bequest distributed to middle-aged agents, who invest less in capital.

This result provides an argument in favour of a reduction of real estate taxation, which may be quite significant, as in France (see Conseil des Prélèvements Obligatoires, 2018).

\section{Concluding remarks}

In this paper, we present a three-period OLG model with capital accumulation, debt, real estate and bequests. Our model presents three features. First, households realise different investments at different period of life. They borrow when young to buy a real estate asset for their old age and save when middle-aged to transfer resources to their old age. Second, households face a binding borrowing constraint. Because of credit market imperfections, they must pledge their wages and their real estate asset as collaterals. Third, households behave altruistically by leaving bequests to their children.

We exhibit the existence of a steady state with a real estate bubble accompanied by a boom in physical capital and aggregate output. This result mainly relies on the existence of altruism in our model. Without altruism, middle-aged households have not a high enough income to sustain a higher level of capital in the presence of a real estate bubble. There is no room for such a bubble. Moreover, we show that a productive real estate bubble exists whatever the type of collateral (fundamental or bubbly collateral) required by lenders on the credit market.

We further analyse the effects of real estate taxation on capital accumulation. We show that an increase of real estate taxation dampens capital accumulation, which is harmful for the real economy. Therefore, our result provides an argument against the implementation of taxation on unproductive assets as real estate.

\section{Appendix}

\subsection{Households' behaviour}

We maximize the Lagrangian function:

$$
\begin{aligned}
& \ln c_{1, t}+\beta \ln c_{2, t+1}+\beta^{2} \ln c_{3, t+2}+\operatorname{\delta ln}\left(\phi w_{t+2}+x_{t+2}\right) \\
& +\lambda_{1, t}\left(w_{t}+d_{t}^{y}-c_{1, t}-p_{t} h_{t+1}\right)+\lambda_{2, t+1}\left(\phi w_{t+1}+x_{t+1}-c_{2, t+1}-R_{t+1}^{d} d_{t}^{y}-k_{t+2}-d_{t+1}^{m}\right) \\
& +\lambda_{3, t+2}\left(p_{t+2} h_{t+1}+R_{t+2}^{d} d_{t+1}^{m}+R_{t+2} k_{t+2}-c_{3, t+2}-x_{t+2}\right) \\
& +\lambda_{4, t+1}\left(\theta_{1} p_{t+1} h_{t+1}+\theta_{2} \phi w_{t+1}-R_{t+1}^{d} d_{t}^{y}\right)
\end{aligned}
$$

with respect to $\left(c_{1, t}, c_{2, t+1}, c_{3, t+2}, k_{t+2}, d_{t}^{y}, d_{t+1}^{m}, h_{t+1}, x_{t+2}, \lambda_{1, t}, \lambda_{2, t+1}, \lambda_{3, t+2}, \lambda_{4, t+1}\right)$. 
First-order conditions are given by:

$$
\begin{aligned}
& c_{1, t} \quad: \quad \frac{1}{c_{1, t}}=\lambda_{1, t} \\
& c_{2, t+1}: \frac{\beta}{c_{2, t+1}}=\lambda_{2, t+1} \\
& c_{3, t+1}: \frac{\beta^{2}}{c_{3, t+2}}=\lambda_{3, t+2} \\
& h_{t+1}: \quad p_{t} \lambda_{1, t}-p_{t+2} \lambda_{3, t+2}-\theta_{1} p_{t+1} \lambda_{4, t+1}=0 \\
& x_{t+2} \quad: \quad \lambda_{3, t+2}-\frac{\delta}{\phi w_{t+2}+x_{t+2}}=0 \\
& d_{t}^{y}: \quad \lambda_{1, t}=R_{t+1}^{d}\left(\lambda_{2, t+1}+\lambda_{4, t+1}\right) \\
& d_{t+1}^{m} \quad: \quad \lambda_{2, t+1}=R_{t+2}^{d} \lambda_{3, t+2} \\
& k_{t+2} \quad: \quad \lambda_{2, t+1}=R_{t+2} \lambda_{3, t+2} \\
& \lambda_{4, t+1}\left(\theta_{1} p_{t+1} h_{t+1}+\theta_{2} \phi w_{t+1}-R_{t+1}^{d} d_{t}\right)=0
\end{aligned}
$$

From Eqs. (62)-(63), we get : $R_{t+2}=R_{t+2}^{d}$. Physical capital and deposit are perfect substitutes. From Eqs. (61) and (63), one has:

$$
\lambda_{4, t+1}=\frac{\lambda_{1, t}}{R_{t+1}^{d}}-R_{t+2} \lambda_{3, t+2}
$$

We restrict our attention on the case where $\lambda_{4, t+1}>0$. Substituting Eqs. (56)-(58) and (65) into Eqs. (59)-(63), one has :

$$
\begin{aligned}
\frac{\beta^{2}}{c_{3, t+2}}\left(p_{t+2}-\theta_{1} p_{t+1} R_{t+2}\right) & =\frac{1}{c_{1, t}}\left(p_{t}-\theta_{1} \frac{p_{t+1}}{R_{t+1}}\right) \\
\frac{\beta^{2}}{c_{3, t+2}} & =\frac{\delta}{\phi w_{t+2}+x_{t+2}} \\
\frac{1}{c_{2, t+1}} & =R_{t+2}^{d} \frac{\beta}{c_{3, t+2}} \\
\theta_{1} p_{t+1} h_{t+1}+\theta_{2} \phi w_{t+1} & =R_{t+1}^{d} d_{t}
\end{aligned}
$$

\subsection{Proof of Proposition 1}

One can easily show that $\underline{R}<1$ if and only if $\delta>\hat{\delta}$. The borrowing constraint is binding if $c_{3}>\beta^{2} \underline{R}^{2} c_{1}$. This inequality is equivalent to:

$$
A_{1}>\underline{R}\left(s \underline{R}+A_{3}\right)
$$

Since $\underline{R}<1$ under $\delta>\hat{\delta}$, inequality (70) is satisfied if

$$
A_{1}>s \underline{R}+A_{3}
$$


We can write $A_{1}$ and $s \underline{R}+A_{3}$ as continuous functions of $\phi$ and $\theta_{2}$ :

$$
\begin{aligned}
A_{1} & =\frac{1+\phi\left[1+\left(1+\theta_{2}\right) s\right]}{\beta^{2}+\delta} \equiv \operatorname{LHS}\left(\phi, \theta_{2}\right) \\
s \underline{R}+A_{3} & =s \frac{\beta+\beta^{2}+\delta+\phi\left[\left(1+\theta_{2} s\right)\left(\beta+\beta^{2}+\delta\right)+\beta s\right]}{\delta+\phi\left[(1+s) \delta-\beta^{2} \theta_{2} s\right]}+\phi \theta_{2} s \equiv \operatorname{RHS}\left(\phi, \theta_{2}\right)
\end{aligned}
$$

Note that

$$
\begin{aligned}
\operatorname{LHS}(\phi, 0) & =\frac{1+\phi[1+s]}{\beta^{2}+\delta} \\
\operatorname{RHS}(\phi, 0) & =s \frac{\beta+\beta^{2}+\delta+\phi\left[\beta(1+s)+\beta^{2}+\delta\right]}{\delta+\phi(1+s) \delta}
\end{aligned}
$$

For $\theta_{2}=0$, Inequality (70) is satisfied if $\operatorname{LHS}(\phi, 0)>\operatorname{RHS}(\phi, 0)$. Note that $\operatorname{LHS}(\phi, 0)$ is an increasing function of $\phi$ and $R H S(\phi, 0)$ a decreasing function of $\phi$. We have $L H S(+\infty, 0)>$ $R H S(+\infty, 0)$ and $\operatorname{LHS}(1,0)<R H S(1,0)$ if $\delta$ is sufficiently high. Therefore, it exists a threshold $\underline{\phi}_{0}>1$ such that for $\phi>\underline{\phi}_{0}, \operatorname{LHS}(\phi, 0)>\operatorname{RHS}(\phi, 0)$. Note that $\operatorname{LHS}\left(\phi, \theta_{2}\right)$ and $\operatorname{RHS}\left(\phi, \theta_{2}\right)$ are both increasing functions of $\theta_{2}$. Moreover, for $\delta$ high enough, $\operatorname{LHS}(+\infty, 1)<\operatorname{RHS}(+\infty, 1)$. By continuity, there exist thresholds $\bar{\theta}_{2} \in(0,1)$ and $\underline{\phi}>1$ such that for $\theta_{2}<\overline{\theta_{2}}$ and $\phi>\underline{\phi}$, $\operatorname{LHS}\left(\phi, \theta_{2}\right)>\operatorname{RHS}\left(\phi, \theta_{2}\right)$. Therefore, if $\delta$ is sufficiently high such that $\delta>\hat{\delta}, \phi>\underline{\phi}$ and $\theta_{2}<\overline{\theta_{2}}$, Proposition 1 follows.

\subsection{Proof of Proposition 2}

A bubbly steady state $\bar{R}$ is a solution of $G(R)=H(R)$, where $G(R)$ and $H(R)$ satisfy (28)-(29).

We start by determining the admissible range of values for $R$. We have already seen that $\theta_{1}<R<1$. We remind that we restrict our attention to the existence of a productive bubble (i.e. $\bar{R}<\underline{R})$. As $p=R G(R) a, B_{1}+R B_{3}$ must be negative to get a positive bubble.

As $B_{1}=\theta_{1}+\left(1+\theta_{1}\right) \beta /\left(\beta^{2}+\delta\right)>0, B_{1}+R B_{3}<0$ implies $R>-B_{1} / B_{3}$ with $B_{3}=$ $\left(\beta^{2} \theta_{1}-\delta\right) /\left(\beta^{2}+\delta\right)<0$. Note that under Assumption $2(\delta>\bar{\delta}), B_{3}<0$ and $-B_{1} / B_{3}>\theta_{1}$. Then, the possible admissible range of values for productive bubbles is $R \in\left(-B_{1} / B_{3}, \underline{R}\right)$, with $\underline{R}<1$.

To prove the existence of a stationary solution $\bar{R} \in\left(-B_{1} / B_{3}, \underline{R}\right)$, we use the continuity of $G(R)$ and $H(R)$. Note that $G(R)$ has a vertical asymptote at $R=-B_{1} / B_{3}$ and is a decreasing and continuous function of $R$ when $R$ increases to $\underline{R}$. $H(R)$ has two vertical asymptotes at $R=\theta_{1}<$ $-B_{1} / B_{3}$ and $R=\left(1+A_{2}\right) / \theta_{1}>1$. From Eqs. (28) and (29), we determine the boundary values of $\mathrm{G}(\mathrm{R})$ and $\mathrm{H}(\mathrm{R})$ :

$$
\begin{aligned}
\lim _{R \rightarrow-B_{1} / B_{3}} G(R) & =+\infty \\
\lim _{R \rightarrow \underline{R}} G(R) & =0 \\
\lim _{R \rightarrow-B_{1} / B_{3}} H(R) & =\frac{\left(B_{1} / B_{3}+\theta_{1}\right) A_{1}+\left(1+\theta_{1} B_{1} / B_{3}\right)\left(-s B_{1} / B_{3}+A_{3}\right)}{\left(-B_{1} / B_{3}-\theta_{1}\right)\left(A_{2}+1+\theta_{1} B_{1} / B_{3}\right)} \\
\lim _{R \rightarrow \underline{R}} H(R) & =\frac{-\left(\underline{R}-\theta_{1}\right) A_{1}+\left(1-\theta_{1} \underline{R}\right)\left(s \underline{R}+A_{3}\right)}{\left(\underline{R}-\theta_{1}\right)\left(A_{2}+1-\theta_{1} \underline{R}\right)}
\end{aligned}
$$


We have $\lim _{R \rightarrow-B_{1} / B_{3}} H(R)<\lim _{R \rightarrow-B_{1} / B_{3}} G(R)$. The existence of a steady state $\bar{R} \in$ $\left(-B_{1} / B_{3}, \underline{R}\right)$, solving $G(R)=H(R)$, is ensured by $0<H(\underline{R})$, namely:

$$
A_{1}<\frac{1-\theta_{1} \underline{R}}{\underline{R}-\theta_{1}}\left(s \underline{R}+A_{3}\right)
$$

Note that $\left(1-\theta_{1} \underline{R}\right) /\left(\underline{R}-\theta_{1}\right)>1$ if and only if $\underline{R}<1$. Using the proof of Proposition 1 , Inequality (76) is in accordance with Inequality (71) and satisfied by continuity argument if $\phi$ close but larger than $\phi$ and $\theta_{2} \in\left(0, \bar{\theta}_{2}\right)$, because it ensures that $A_{1}$ is larger but close to $s \underline{R}+A_{3}$.

We ensure now that the set $\left(-B_{1} / B_{3}, \underline{R}\right)$ is non-empty. The set $\left(-B_{1} / B_{3}, \underline{R}\right)$ is non-empty if and only if $-B_{1} / B_{3}<\underline{R}$ with:

$$
\begin{aligned}
-\frac{B_{1}}{B_{3}} & =\frac{\delta \theta_{1}+\beta+\theta_{1} \beta(1+\beta)}{\delta-\beta^{2} \theta_{1}} \equiv \operatorname{LHS}\left(\delta, \theta_{1}\right) \\
\underline{R} & =\frac{\left(1+\phi+\phi \theta_{2} s\right)\left(\delta+\beta+\beta^{2}\right)+\beta \phi s}{\delta(1+\phi+\phi s)-\theta_{2} \beta^{2} \phi s} \equiv R H S(\delta)
\end{aligned}
$$

Note that $\operatorname{LHS}\left(\delta, \theta_{1}\right)$ and $R H S(\delta)$ are decreasing functions of $\delta$ and we have that:

$$
\begin{aligned}
\lim _{\delta \rightarrow+\infty} \operatorname{LHS}\left(\delta, \theta_{1}\right) & =\theta_{1} \\
\lim _{\delta \rightarrow+\infty} \operatorname{RHS}(\delta) & =\frac{1+\phi+\phi \theta_{2} s}{1+\phi+\phi s}<1
\end{aligned}
$$

We deduce that $\lim _{\delta \rightarrow+\infty} L H S\left(\delta, \theta_{1}\right)<\lim _{\delta \rightarrow+\infty} R H S(\delta)$ if and only if:

$$
\theta_{1}<\frac{1+\phi+\phi \theta_{2} s}{1+\phi+\phi s} \equiv \bar{\theta}_{1}
$$

If $\theta_{1}<\bar{\theta}_{1}$, there exists a threshold $\tilde{\delta}>0$ such that for $\delta>\tilde{\delta}, \operatorname{LHS}\left(\delta, \theta_{1}\right)<R H S(\delta)$. Therefore, if $\theta_{1}<\bar{\theta}_{1}$ and $\delta>\tilde{\delta}$, the set $\left(-B_{1} / B_{3}, \underline{R}\right)$ is nonempty.

To conclude, if $\phi$ is close but larger than $\phi, \theta_{2}<\bar{\theta}_{2}, \theta_{1}<\bar{\theta}_{1}$ and $\delta$ sufficiently high such that $\delta>\max \{\tilde{\delta}, \bar{\delta}, \widehat{\delta}\}$, there exists a steady state $\overline{\bar{R}} \in\left(-B_{1} / B_{3}, \underline{R}\right)$ which coexists with the bubbleless one $\underline{R}$.

To prove uniqueness, we observe that the equation $H(R)=G(R)$ is equivalent to a polynomial of degree 3, i.e. has at most three solutions. Since $\lim _{R \rightarrow\left(1+A_{2}\right) / \theta_{1}} H(R)=-\infty$ and $\lim _{R \rightarrow\left(1+A_{2}\right) / \theta_{1}} G(R)$ is finite, we have $\lim _{R \rightarrow\left(1+A_{2}\right) / \theta_{1}} H(R)<\lim _{R \rightarrow\left(1+A_{2}\right) / \theta_{1}} G(R)$. We have established that $\lim _{R \rightarrow \underline{R}} H(R)>\lim _{R \rightarrow \underline{R}} G(R)$. This means that an odd number of solutions to the equation $H(R)=\overline{G(R)}$ belong to $\left(\underline{R},\left(1+A_{2}\right) / \theta_{1}\right)$. Since we also have $\lim _{R \rightarrow-B_{1} / B_{3}} G(R)>$ $\lim _{R \rightarrow-B_{1} / B_{3}} H(R)$, there are an odd number of solutions to $H(R)=G(R)$ that belong $\left(-B_{1} / B_{3}, \underline{R}\right)$. Since there are at most three solutions, the solution $\bar{R}$ in this last interval is unique.

\subsection{Households' behaviour in the model with taxation}

We maximize the Lagrangian function:

$$
\begin{aligned}
& \operatorname{lnc} c_{1, t}+\beta \ln c_{2, t+1}+\beta^{2} \ln c_{3, t+2}+\delta \ln \left[\phi w_{t+2}+x_{t+2}\right] \\
& +\lambda_{1, t}\left(w_{t}+d_{t}^{y}-c_{1, t}-p_{t} h_{t+1}\right)+\lambda_{2, t+1}\left[\phi w_{t+1}+x_{t+1}-c_{2, t+1}-R_{t+1}^{d} d_{t}^{y}-k_{t+2}-d_{t+1}^{m}\right] \\
& +\lambda_{3, t+2}\left[\left(1-\tau_{h}\right) p_{t+2} h_{t+1}+R_{t+2}^{d} d_{t+1}^{m}+R_{t+2} k_{t+2}-c_{3, t+2}-x_{t+2}\right] \\
& +\lambda_{4, t+1}\left(\theta_{1} p_{t+1} h_{t+1}+\theta_{2} \phi w_{t+1}-R_{t+1}^{d} d_{t}^{y}\right)
\end{aligned}
$$


with respect to $\left(c_{1, t}, c_{2, t+1}, c_{3, t+2}, k_{t+2}, d_{t}^{y}, d_{t+1}^{m}, h_{t+1}, x_{t+2}, \lambda_{1, t}, \lambda_{2, t+1}, \lambda_{3, t+2}, \lambda_{4, t+1}\right)$. First-order conditions are given by:

$$
\begin{aligned}
& \frac{1}{c_{1, t}}=\lambda_{1, t}, \quad \frac{\beta}{c_{2, t+1}}=\lambda_{2, t+1}, \quad \frac{\beta^{2}}{c_{3, t+2}}=\lambda_{3, t+2} \\
& p_{t} \lambda_{1, t}=\left(1-\tau_{h}\right) p_{t+2} \lambda_{3, t+2}+\theta_{1} p_{t+1} \lambda_{4, t+1} \\
& \lambda_{3, t+2}=\frac{\delta}{\phi w_{t+2}+x_{t+2}} \\
& \lambda_{1, t}=R_{t+1}^{d}\left(\lambda_{2, t+1}+\lambda_{4, t+1}\right) \\
& \lambda_{2, t+1}=R_{t+2}^{d} \lambda_{3, t+2}, \quad \lambda_{2, t+1}=R_{t+2} \lambda_{3, t+2}
\end{aligned}
$$

From Eq. (83), we get $R_{t+2}=R_{t+2}^{d}$. From Eqs. (82) and (83), one has:

$$
\lambda_{4, t+1}=\frac{\lambda_{1, t}}{R_{t+1}^{d}}-R_{t+2}^{d} \lambda_{3, t+2}
$$

We restrict our attention on the case where $\lambda_{4, t+1}>0$, i.e. $\lambda_{1, t}>R_{t+1}^{d} R_{t+2}^{d} \lambda_{3, t+2}$. Substituting Eq. (79) into Eqs. (80), (81) and (83), we deduce:

$$
\begin{aligned}
\frac{\beta^{2}}{c_{3, t+2}}\left[\left(1-\tau_{h}\right) p_{t+2}-\theta_{1} p_{t+1} R_{t+2}\right] & =\frac{1}{c_{1, t}}\left[p_{t}-\theta_{1} \frac{p_{t+1}}{R_{t+1}}\right] \\
\frac{1}{c_{2, t+1}} & =R_{t+2} \frac{\beta}{c_{3, t+2}} \\
R_{t+2}^{d} & =R_{t+2} \\
\frac{\beta^{2}}{c_{3, t+2}} & =\frac{\delta}{\phi w_{t+2}+x_{t+2}} \\
\theta_{1} p_{t+1} h_{t+1}+\theta_{2} \phi w_{t+1} & =R_{t+1} d_{t}^{y} \\
\beta^{2} R_{t+1} R_{t+2} c_{1, t} & <c_{3, t+2} \\
x_{t+2} & >0
\end{aligned}
$$

\subsection{Proof of Proposition 5}

The existence of the steady state is obtained because $G_{T}(R)>H_{T}(R)$ when $R$ tends to $-\tilde{B}_{1} / \tilde{B}_{3}$ and $G_{T}(R)<H_{T}(R)$ when $R$ tends to $\underline{R}_{T}$. Uniqueness allows to deduce that at the steady state, we have $G_{T}^{\prime}(R)<H_{T}^{\prime}(R)$.

Using Eq. (53), we have:

$$
\frac{d \bar{R}_{T}}{d\left(1-\tau_{h}\right)}=\frac{\frac{\partial G_{T}\left(\bar{R}_{T}\right)}{\partial\left(1-\tau_{h}\right)}-\frac{\partial H_{T}\left(\bar{R}_{T}\right)}{\partial\left(1-\tau_{h}\right)}}{H_{T}^{\prime}\left(\bar{R}_{T}\right)-G_{T}^{\prime}\left(\bar{R}_{T}\right)}
$$

We start by computing $\partial G_{T}\left(\bar{R}_{T}\right) / \partial\left(1-\tau_{h}\right)$. Note that $B_{2}$ and $B_{4}$ do not depend on $\tau_{h}$, while we have:

$$
\frac{\partial\left(\tilde{B}_{1}+R \tilde{B}_{3}\right)}{\partial\left(1-\tau_{h}\right)}=\frac{\beta-\delta R}{\beta^{2}+\delta}<0
$$


because $R>\theta_{1}$ and $\delta>\beta / \theta_{1}$. We deduce that:

$$
\frac{\partial G_{T}\left(\bar{R}_{T}\right)}{\partial\left(1-\tau_{h}\right)}=-\frac{G_{T}\left(\bar{R}_{T}\right)}{\tilde{B}_{1}+\bar{R}_{T} \tilde{B}_{3}} \frac{\beta-\delta \bar{R}_{T}}{\beta^{2}+\delta}<0
$$

because $\tilde{B}_{1}+\bar{R}_{T} \tilde{B}_{3}<0$.

Using Eq. (55), $H_{T}(R)$ can be rewritten as follows:

$$
H_{T}(R)=\frac{\beta^{2}+\delta}{R-\theta_{1}} \frac{\left(1-\tau_{h}-\theta_{1} R\right)\left(s R+A_{3}\right)-\left(R-\theta_{1}\right) A_{1}}{\left(1-\tau_{h}\right)\left(1+\beta^{2}+\delta\right)+\theta_{1}\left[1-\left(\beta^{2}+\delta\right) R\right]}
$$

Obviously, $\partial H_{T}\left(\bar{R}_{T}\right) / \partial\left(1-\tau_{h}\right)$ has the sign of its numerator, i.e.

$$
\left(s \bar{R}_{T}+A_{3}\right) \theta_{1}\left(1+\bar{R}_{T}\right)+\left(1+\beta^{2}+\delta\right) A_{1}\left(\bar{R}_{T}-\theta_{1}\right)>0
$$

Using Eq. (92), we deduce that $d \bar{R}_{T} / d\left(1-\tau_{h}\right)<0$. This means that $\bar{R}_{T}$ increases with $\tau_{h}$, whereas $\bar{a}_{T}$ decreases with $\tau_{h}$.

\section{References}

[1] Arce, O. and Lopez-Salido, D. (2011), "Housing bubbles", American Economic Journal: Macroeconomics 3, 212-241.

[2] Basco, S. (2014), "Globalization and financial development: A model of the dot-com and the housing bubbles", Journal of International Economics 92, 78-94.

[3] Bosi, S., Ha-Huy, T., Le Van C., Pham C.-T. and N.-S. Pham (2018), "Financial bubbles and capital accumulation in altruistic economies", Journal of Mathematical Economics 75, 125-139.

[4] Campbell, J. and G. Mankiw (1989), "Consumption, income and interest rates: Reinterpreting the time series evidence,"In: O. Blanchard and S. Fisher (Eds.) NBER Macroeconomics Annual, MIT Press, Cambridge MA, 185-216.

[5] Conseil des Prélèvements Obligatoires (2018), "Les prélèvements obligatoires sur le capital des ménages", 1-140.

[6] Crook, J. and S. Hochguertel (2005), "Household debt and credit constraints: Evidence from OECD countries", Credit Research Center, University of Edinburgh Working Paper Series No. $05 / 02$.

[7] Dynan, K. E., J. Skinner and S. P. Zeldes (2004), "Do the rich save more?", Journal of Political Economy 112, 397-444.

[8] Fahri, E. and J. Tirole (2012), "Bubbly liquidity", Review of Economic Studies 79, 678-706.

[9] Hirano, T. and N. Yanagawa (2017), "Asset bubbles, endogenous growth, and financial frictions", Review of Economic Studies 84, 406-443.

[10] Huber, S. (2018), "Preference for housing services and rational house price bubbles", miméo. 
[11] Iacoviello, M. (2004), "Consumption, house prices, and collateral constraints: A structural econometric analysis," Journal of Housing Economics 13, 304-320.

[12] IMF - International Monetary Fund (2015), World Economic Outlook, Uneven Growth: Shortand Long-Term Factors.

[13] Jappelli, T. (1990), "Who is credit constrained in the US economy?," Quarterly Journal of Economics 105, 219-234.

[14] Kamihigashi, T. (2008): "The spirit of capitalism, stock market bubbles and output fluctuations ", International Journal of Economic Theory 4, 3-28.

[15] Kiyotaki, N. and J. Moore (1997), "Credit cycles ", Journal of Political Economy 4, 211-248.

[16] Kocherlakota, N.R. (2009), "Bursting bubbles: Consequences and cures", University of Minnesota working paper.

[17] Kotlikoff L. J. and L. H. Summers (1981), "The role of intergenerational transfers in aggregate capital accumulation", Journal of Political Economy 89, 706-732.

[18] Leung, C. (2004), "Macroeconomics and housing: A review of the literature ", Journal of Housing Economics 13, 249-267.

[19] Loi $n^{0}$ 2017-1837 du 30 décembre 2017 de finances pour 2018.

[20] Ludvigson, S. (1998), "Consumption and credit: A model of time-varying liquidity constraints", The Review of Economics and Statistics 81, 434-447.

[21] Lustig, H. and S. Van Nieuwerburgh (2010), "How much does household collateral constrain regional risk sharing?", Review of Economic Dynamics 13, 265-294.

[22] Marcet, A. and K. Singleton (1999), "Equilibrium asset prices and saving of heterogeneous agents in the presence of incomplete markets and portfolio constraints", Macroeconomic Dynamics 3, 243-277.

[23] Martin, A. and J. Ventura (2011), "Theoretical notes on bubbles and the current crisis", IMF Economic Review 59, 6-40.

[24] Martin, A. and J. Ventura (2012), "Economic growth with bubbles", American Economic Review 102, 3033-58.

[25] Martin, A. and J. Ventura (2016), "Managing credit bubbles ", Journal of the European Economic Association 14, 753-789.

[26] Mera, K. and B. Renaud (2000), Asia's Financial Crisis and the Role of Real Estate, Taylor and Francis, New-York, USA.

[27] Miao, J. and P. Wang (2018), "Asset bubbles and credit constraints", forthcoming in American Economic Review.

[28] Miao, J., Wang. P and J. Zhou (2015), "Housing bubbles and policy analysis", 2015 Meeting Papers 1056, Society for Economic Dynamics. 
[29] Raurich, X. and Seegmuller (2015), "On the interplay between speculative bubbles and productive investment", AMSE Working Paper 2015-42.

[30] Raurich, X. and Seegmuller (2017), "Income distribution by age group and productive bubbles", AMSE Working Paper 2017-40.

[31] Tirole, J. (1985), "Asset bubbles and overlapping generations", Econometrica 53, 1071-1100.

[32] Zhao, B. (2015), "Rational housing bubble", Economic Theory 60, 141-201. 